\title{
Microstructural stability and grain growth kinetics in an extruded fine-grained $\mathrm{Mg}-\mathrm{Gd}-\mathrm{Y}-\mathrm{Zr}$ alloy
}

\author{
R. Alizadeh \\ ${ }^{a}$ School of Metallurgical and Materials Engineering, College of Engineering, \\ University of Tehran, Tehran, Iran (mrbalizadeh@ut.ac.ir) \\ R. Mahmudi ${ }^{\mathrm{a}^{*}}$ \\ ${ }^{a}$ School of Metallurgical and Materials Engineering, College of Engineering, \\ University of Tehran, Tehran, Iran (mahmudi@ut.ac.ir) \\ *Corresponding author: e-mail: mahmudi@ut.ac.ir; \\ Phone: +98 218208 4137, Fax: +982188006076
}

T.G. Langdon ${ }^{\mathrm{b}}$

${ }^{\mathrm{b}}$ Materials Research Group, Faculty of Engineering and the Environment, University of Southampton, Southampton SO17 1BJ, U.K.

(T.G.Langdon@soton.ac.uk)

\author{
A.H.W. Ngan ${ }^{\mathrm{c}}$ \\ ${ }^{c}$ Department of Mechanical Engineering, The University of Hong Kong, \\ Pokfulam Road, Hong Kong \\ (hwngan@hku.hk)
}




\title{
Microstructural stability and grain growth kinetics in an extruded fine-grained $\mathrm{Mg}-\mathrm{Gd}-\mathrm{Y}-\mathrm{Zr}$ alloy
}

\author{
R. Alizadeh ${ }^{\mathrm{a}}$, R. Mahmudi ${ }^{\mathrm{a}}$, T.G. Langdon ${ }^{\mathrm{b}}$, A.H.W. Ngan ${ }^{\mathrm{c}}$ \\ ${ }^{a}$ School of Metallurgical and Materials Engineering, College of Engineering, \\ University of Tehran, Tehran, Iran \\ ${ }^{\mathrm{b}}$ Materials Research Group, Faculty of Engineering and the Environment, \\ University of Southampton, Southampton SO17 1BJ, U.K. \\ ${ }^{c}$ Department of Mechanical Engineering, The University of Hong Kong, \\ Pokfulam Road, Hong Kong \\ *Corresponding author: e-mail: mahmudi@ut.ac.ir; \\ Phone: +98 218208 4137, Fax: +982188006076
}

\begin{abstract}
The grain growth kinetics of an extruded fine-grained $\mathrm{Mg}-9 \mathrm{Gd}-4 \mathrm{Y}-0.4 \mathrm{Zr}$ (wt.\%) alloy was investigated by static annealing in the temperature range of $673-773 \mathrm{~K}$. In addition to the microstructural evolution, textural evolution of the material was also studied during high temperature exposure. The material revealed an unusual basal texture in the extruded condition which was weakened after annealing. The material behavior can be divided into two temperature regimes; namely, from $673 \mathrm{~K}$ to $723 \mathrm{~K}$ and from $723 \mathrm{~K}$ to $773 \mathrm{~K}$. According to the obtained data, although the material shows superior thermal stability in comparison with the conventional $\mathrm{Mg}$ alloys, it looses most of its resistance to grain growth at temperatures higher than $673 \mathrm{~K}$. It was observed that although the $\operatorname{Mg}_{3}(\mathrm{Gd}, \mathrm{Y})$ precipitates have sufficient thermal stability to restrict grain growth, significant grain growth occurs at the highest temperatures where increased mobility of the grain boundaries seems to be dominant. However, there is restricted growth at lower temperatures, where the grain growth is controlled by lattice self-diffusion.
\end{abstract}

Keywords: Boundary mobility; Grain growth; $\mathrm{Mg}-\mathrm{Gd}-\mathrm{Y}-\mathrm{Zr}$ alloy; Texture 


\section{Introduction}

Magnesium alloys have been the subject of many investigations because of their low density, good castability, high specific strength and stiffness combined with their reasonable cost. Despite these advantages, $\mathrm{Mg}$ alloys suffer from poor room temperature formability because of the limited slip systems in their hexagonal close-packed (hcp) structure [1]. In addition, there are limitations associated with heating simple magnesium alloys to high temperatures because the microstructures of fine-grained alloys tend to be unstable and exhibit extensive grain growth. Attempts have been made to improve their thermal stability by the addition of different alloying elements and in this respect it was reported that the addition of gadolinium $(\mathrm{Gd})$ and other rare earth (RE) elements leads to a remarkable improvement in the mechanical properties at high temperatures due to solution and precipitation hardening [2-5].

Recently, excellent thermal stability was achieved in a series of $\mathrm{Mg}-\mathrm{Gd}$ alloys which has permitted the occurrence of extensive superplasticity in these alloys. The microstructure of the $\mathrm{Mg}-\mathrm{Gd}$ alloy was investigated in earlier research [6-8]. The high thermal stability is usually related to the stable precipitates present in the microstructure of these alloys. It has been reported that different precipitates such as $\mathrm{Mg}_{24} \mathrm{Gd}_{5}, \mathrm{Mg}_{5} \mathrm{Gd}$ and $\mathrm{Mg}_{3} \mathrm{Gd}$ can be formed in these alloys. Thus, the most important feature of $\mathrm{Mg}-\mathrm{Gd}$ alloys is their excellent resistance to grain growth which permits the use of high testing temperatures and provides the ability to achieve high strain rate sensitivities [9]. Excellent resistance to grain growth up to $573 \mathrm{~K}$ was reported for an $\mathrm{Mg}-10 \mathrm{Gd}$ alloy processed by high pressure torsion [10] and another report showed no significant grain growth at a temperature of $673 \mathrm{~K}$ while studying the superplastic behavior of an extruded $\mathrm{Mg}-8 \mathrm{Gd}-$ 
$3 \mathrm{Y}-0.5 \mathrm{Zr}$ alloy in the temperature range of $673-763 \mathrm{~K}$ [11]. It was also reported that additions of only $0.3-0.7 \mathrm{Gd}$ to an $\mathrm{Mg}-2 \mathrm{Zn}$ alloy suppressed grain growth during the annealing process [12]. Although excellent resistance to grain growth has been reported for several different $\mathrm{Mg}-\mathrm{Gd}$ alloys, there has been no comprehensive study of the grain growth kinetics in these alloys, especially at temperatures higher than $673 \mathrm{~K}$. Also, microstructural and textural evolutions of these alloy during grain growth has not been well investigated in the literature. Accordingly, the aim of this investigation was to study the grain growth kinetics of an extruded $\mathrm{Mg}-9 \mathrm{Gd}-4 \mathrm{Y}-0.4 \mathrm{Zr}$ alloy in the temperature range of 673-773 K, where earlier results demonstrated the potential for achieving superplastic behavior in this alloy [13]. Microstructure and texture of the alloy are also investigated in detail to rationalize different behavior of the material at the selected temperatures.

\section{Experimental material and procedures}

The material used in this investigation was a $\mathrm{Mg}-9$ wt.\% Gd-4 wt.\% Y-0.4 wt.\% $\mathrm{Zr}$ alloy (hereafter, all alloy compositions are in weight percent, unless otherwise stated). The alloy was prepared from high purity $\mathrm{Mg}$ and $\mathrm{Mg}-30 \mathrm{Gd}, \mathrm{Mg}-30 \mathrm{Y}$ and $\mathrm{Mg}-30 \mathrm{Zr}$ master alloys which were melted in an electrical furnace under a covering flux. Extrusion was conducted using an extrusion ratio of 19:1 at a temperature of $673 \mathrm{~K}$. Slices of $\sim 1 \mathrm{~mm}$ thickness were cut from the extruded bars in directions perpendicular to the extrusion axis and then ground to thicknesses of $\sim 0.7 \mathrm{~mm}$. The microstructure of the material was examined by optical and scanning electron microscopy (SEM) and the grain size and grain size distribution was measured. At least 500 grains were considered for the grain size distributions and the weighted average grain diameters were obtained using a Clemex 
professional image analysis program according to the ASTM E112 standard. The electron backscattered diffraction (EBSD) was used to study the misorientation angles of grain boundaries and also texture evolution. The specimen preparation for EBSD involved SiC paper grinding and diamond paste polishing, followed by a $3-\mathrm{h}$ vibratory polishing with an alcohol based alumina.

\section{Experimental results}

\section{Microstructural evolution}

The transverse and longitudinal microstructures of the alloy in the as-extruded condition are shown in Fig. 1. It is apparent that both microstructures consist of equiaxed grains, implying that dynamic recrystallization (DRX) occurred during the hot extrusion process. Accordingly, no effects of deformed and elongated grains were observed in the longitudinal direction and thus further microstructural investigations are focused exclusively on the transverse direction. In fine-grained materials, the uniformity of the grain size distribution is important in addition to the average grain size because the width of the distribution may affect the mechanical properties. Accordingly, the grain size distribution data collected from a number of samples are shown in Fig. 1c. It is clear that the results show a near-normal distribution with an average grain size of $\sim 8.6 \mu \mathrm{m}$ and a standard deviation (S.D.) of $\sim 2.0 \mu \mathrm{m}$. This grain size is slightly smaller than the grain size of $\sim 10 \mu \mathrm{m}$ reported earlier in an investigation using lower extrusion ratios [9]. It can be seen from Fig. 1c that all grains fall within the narrow range of 4.7-14.2 $\mu \mathrm{m}$ so that there is a narrow grain size range in this condition. 
SEM micrographs of the alloy are shown in Fig. 2. As can be observed, the microstructure consists of some cubic precipitates with different sizes, located both at grain boundaries and inside the grains. Fig. $2 \mathrm{~b}$ shows a relatively large cubic precipitate (about $6 \mu \mathrm{m}$ in diameter) near the center of a grain. EDS analysis was performed on different (about 10) cubic precipitates and also the surrounding particle-free matrix to determine the chemical compositions and the average values were reported. EDS point- and line-scan results are presented in Fig. 3. EDS line-scan results, performed on a relatively large cubic particle, demonstrate that this particle seem to be rich in Gd and Y. EDS point-scan results on points $\mathrm{A}, \mathrm{B}$ and $\mathrm{C}$ in Fig. 3 show that the average nominal composition of the cubic precipitates is $\operatorname{Mg}_{72}(\mathrm{Gd}, \mathrm{Y})_{28}$, which can be approximated as $\mathrm{Mg}_{3}(\mathrm{Gd}, \mathrm{Y})$, as suggested by other investigations on similar alloys [9].

In order to study the occurrence of grain growth at high temperatures, static annealing was performed for different times on samples in the temperature range of 673$773 \mathrm{~K}$. This temperature range was selected because earlier research showed these temperatures produced the highest strain rate sensitivities [13]. The microstructure is shown in Fig. 4 after annealing for periods of either 15 min (left column) or 120 min (right column) at different temperatures from 673 to $773 \mathrm{~K}$. To obtain a better understanding of the occurrence of grain growth, the grain size distributions are also shown in Fig. 4 for each annealing condition. It is observed that increases in the annealing time at each temperature lead to increases in the grain size ranges, decreases in intensity of the counts and a general increase in the average grain size. The amounts of these changes are different at each temperature so that different growth kinetics occurs at different temperatures. Also, the 
variations of the standard deviations denote an increased scattering of grain sizes from the average value when increasing either the time or temperature of annealing.

To understand better the microstructural changes at high temperatures, the SEM micrographs of the alloy after annealing for $120 \mathrm{~min}$ at 673,723 and $773 \mathrm{~K}$, are shown in Fig. 5. As is visible in this figure, although the precipitates have restricted grain growth in some grains by pinning the grain boundaries, this behavior is not homogenous throughout all of the microstructure. Thus, the precipitates in the present alloy show the ability to restrict grain growth whenever they have interacted with the grain boundaries. But as shown in this figure, there are many precipitates in the microstructure which are located within the grains and not at the grain boundaries. Another important feature of this figure is that the volume fraction of the precipitates seems to increase in high temperature exposure, due to the precipitation of cubic particles. The precipitation is more severe at 773 K.

A comparison of the EDS line-scan results of the precipitates after annealing for $120 \mathrm{~min}$ at 723 and $773 \mathrm{~K}$ is shown in Fig. 6. Also, the EDS point-scan results on selected precipitates together with the surrounding matrix are summarized in this figure. The results indicate that the precipitates are rich in $\mathrm{Gd}$ and $\mathrm{Y}$, and the average nominal composition seems close to $\mathrm{Mg} 3 \mathrm{Gd}$. However, comparison of the composition of the matrix before and after annealing shows that there has been a slight reduction in the Gd and Y concentrations after high temperature exposure. This is reasonable by considering the volume fraction of precipitates in the annealed samples (Fig. 5). 


\section{Texture evolution through EBSD}

Texture evolution during high temperature exposure is also important for magnesium alloys in addition to the microstructural changes. Accordingly, Fig. 7 exhibits the EBSD orientation maps of the alloy both before and after annealing at $723 \mathrm{~K}$ for 120 min. As can be observed, the as-extruded material possesses a very uniform equiaxed recrystallized grain structure and no deformed or elongated grains are detected in the microstructure. Also, it seems that the (0001) plane of the most of the grains has been aligned perpendicular to the extrusion direction. On the other hand, extensive grain growth together with some changes in the orientation relationships of the grains has occurred by annealing at $723 \mathrm{~K}$. Misorientation histograms of both conditions show that almost all of the grain boundaries are of high-angle type. Also, there is a small shift in the number fraction of the grain boundaries toward higher angles after annealing.

The texture evolutions of the material after extrusion and annealing are shown in Fig. 8. Thus, although the material shows a weak $(10 \overline{\mathbf{1 0}})(1 \mathbf{0 1 0})$ fiber texture, it shows a relatively severe basal texture with maximum intensity of about 8.1 MRD (multiplies of random distribution). The basal texture is in such a way that the (0001) planes are aligned perpendicular to the extrusion direction, in contrast to the most common texture of the nonRE-containing extruded magnesium alloys, since the general trend is that basal planes would be aligned parallel to the extrusion direction. Thus, the material shows an unusual texture in the extruded condition which has rotated about $90^{\circ}$ from the usual basal texture of extruded magnesium alloys and corresponds to an extrusion direction parallel to the caxis, so the prismatic planes are parallel to the extrusion direction. The texture results of the annealed sample reveal a weakened basal texture with maximum intensity of around 
2.3 MRD. It should be mentioned that the texture data were recorded from a large area of about $1.5 \mathrm{~mm} \times 1.5 \mathrm{~mm}$ and thus there is no probability of local heterogeneities in the grain orientations such as shear bands. Fig. 7 also shows that the grains are uniformly distributed in the microstructure.

\section{Grain growth study}

The measured average grain sizes are plotted against the annealing time in Fig. 9 for each annealing temperature. Thus, a generally normal increase in grain size with increasing time is observed at each temperature although there is a relatively sharp increase in grain size after very short annealing times and this sharp increase is more significant at the higher temperatures.

To provide a better representation of the data, Fig. 10 shows a grain growth map of the alloy where the iso-grain growth factor contours are plotted against the annealing temperature and the total time of exposure. The grain growth factor was simply defined as $100 \times\left(D-D_{0}\right) / D_{0}$, where $D$ and $D_{0}$ are the current and initial values of the average grain size, respectively. This plot provides a simple pictorial representation of the resistance of the material to grain growth over the total spectrum of temperature and time. It is reasonable to conclude from this plot that the material resistance to grain growth decreases with increasing time and/or temperature and thus extensive growth may be anticipated at very high temperatures and long annealing times. An interesting conclusion from Fig. 10 is that the grain growth factor of about 93 experienced after 120 min at $673 \mathrm{~K}$ would be attained after a much shorter time of less than 5 min when annealing at either 723 or 773 K. It follows, therefore, that the alloy loses most of its resistance to grain growth at 
temperatures higher than about $673 \mathrm{~K}$. Accordingly, it is reasonable to investigate the grain growth mechanisms occurring at different temperatures.

\section{Discussion}

\section{Microstructural evolution}

According to the Mg-Gd phase diagram [14], Gd has limited solubility in Mg at room temperature. Thus, the microstructure of the alloy in the as-extruded condition consists of a supersaturated solid solution of Gd in Mg. The EDS results of the matrix show that the concentration of $\mathrm{Gd}$ in $\mathrm{Mg}$ decreases slightly after high temperature exposure. This indicates that although solubility of Gd in Mg should increase with temperature (around 18 wt. \% at $773 \mathrm{~K}), \mathrm{Gd}$ has not become dissolved any more at high temperatures even after $120 \mathrm{~min}$. This may arise from the difficult diffusion of large $\mathrm{Gd}$ atoms among the $\mathrm{Mg}$ atoms. However, it seems that there is some precipitation at high temperatures and the volume fraction of precipitates increases with increasing temperature. The EDS results of the precipitates also reveal that there is no considerable change in the chemical composition. In fact, the microstructures of the material showed that $\mathrm{Mg}_{3}(\mathrm{Gd}, \mathrm{Y})$ particles are able to withstand temperatures as high as $773 \mathrm{~K}$, at least for 120 min exposure. These particles are the main reason for the excellent thermal stability of Mg-Gd-Y alloys by comparison with conventional $\mathrm{Mg}-\mathrm{Al}-\mathrm{Zn}$ alloys and can restrict grain growth by pinning the grain boundaries whenever they are located at the grain boundaries. However, even Mg-Gd-Y cannot retain a fine grain structure at temperatures higher than $673 \mathrm{~K}$, because of the increased mobility of grain boundaries and also the faster diffusion rates. 


\section{Texture evolution}

The addition of RE elements to the magnesium alloys leads to distinct microstructures and textures not observed in common magnesium alloys such as AZ31. In this study, the material showed an unusual basal texture, where the basal planes were aligned perpendicular to the extrusion direction. This is in contrast to the general texture of extruded magnesium alloys where the basal planes usually align parallel to the extrusion direction. Such unusual textures have been rarely reported previously in the literature. Robson et al. [15] reported such texture in extruded $\mathrm{Mg}-6 \mathrm{Y}-7 \mathrm{Gd}-0.5 \mathrm{Zr}$ alloy and related it to the dynamic recrystallization of the material during extrusion. Also, they showed that this special texture only occurs at high extrusion ratios, and reported such a texture at an extrusion ratio of 17:1. The interesting point of their research was that the material showed conventional textures at lower extrusion ratios (10:1) [15]. Therefore, it seems that the unusual texture of the extruded material may arise from three important parameters; A) RE elements, B) high extrusion ratio, and C) DRX.

Regarding the effects of RE elements on the texture modification of magnesium alloys, it has been stated that two aspects can be considered: oriented nucleation and oriented growth. From the oriented nucleation aspect, RE elements modify the recrystallization texture by providing potent nucleation sites with orientations distinct from the typical deformation texture via shear band nucleation $(\mathrm{SBN})[16,17]$ and particlestimulated nucleation (PSN) [18]. Regarding the oriented growth aspect, RE elements influence the final texture by affecting the growth advantage of specific orientations through Zener drag [19] or solute drag [20]. Another important effect of RE elements is to activate other slip systems in addition to the basal planes by decreasing the critical resolved 
shear stress (CRSS) of these other systems. In this way, the deformation basal texture would be weaker. However, although the presence of RE elements plays an important role in enhancing the texture of $\mathrm{Mg}$ alloys, their presence cannot be mainly responsible for the observed unusual texture, since such textures were not observed at lower extrusion ratios in RE containing alloys [15]. It seems that the most important effect of high extrusion ratios would be accommodation of large amounts of strain on slip systems which can promote again activation of non-basal slip systems. Accordingly, the high temperature of extrusion deformation, the RE elements and the high extrusion ratios seem to assist the activation of other slip systems in addition to the basal systems. By contrast, the high extrusion ratio used in this study (19:1) would result in a high stored energy in the material which can promote DRX.

It seems that the present unusual texture component arises from dynamic recrystallization. Unlike the discontinuous recrystallization that involves nucleation and nuclei growth, continuous recrystallization does not involve any long-range migration of high-angle grain boundaries (HAGBs). Instead, low-angle sub-boundaries gradually transform in situ into HAGBs through progressive accumulation of dislocations. Dislocation activities during recrystallization can be inferred from the sub-boundary misorientation axes distribution. The sub-boundaries with misorientation axes lying in the basal plane are related with the accumulation of basal dislocations, which has a tendency to rotate the sub-grains to a basal orientation. The sub-boundaries with misorientation axes having an inclination to the basal plane, on the other hand, are thought to correspond to the incorporation of non-basal dislocations and thus correlate with texture randomization. Therefore, it can be concluded that the co-existence of RE elements, high deformation 
temperature and high extrusion ratios will result in the activation of other slip systems in addition to the basal slip. The non-basal dislocations can make the misorientation axes have some inclinations to the basal plane and thus the newly-formed grain can have a different growth advantage from the basal orientation. This means that there would be a growth advantage for the newly-formed grains to align themselves in such a way that their c-axes are aligned parallel to the extrusion axis. The local rotation of the sub-grains as a result of increased non-basal dislocations was also reported as the main reason for the conventional rolling texture weakening in a ZEK100 alloy [21]. The other reason of such growth advantage can be also the RE elements solute or Zener drag effects. Accordingly, the texture of the extruded material was significantly different from the non-RE containing alloys with low extrusion ratios. The texture of the material after annealing shows that grain growth has weakened the recrystallized texture and there would be no strong basal texture after severe grain growth at $723 \mathrm{~K}$.

\section{Grain growth kinetics}

A true understanding of the grain growth kinetics and mechanisms at high temperatures is necessary in order to enhance the high temperature mechanical properties of materials. Accordingly, the measured grain sizes were plotted against time on logarithmic scales in Fig. 11 so that the grain growth exponent is estimated using the following relationship:

$$
D^{n}-D_{0}^{n}=C t \exp (-Q / R T)
$$

where $n$ is the grain growth exponent, $t$ is the annealing time, $Q$ is the activation energy for grain growth, $R$ is the gas constant, $T$ is the absolute temperature and $C$ is a kinetic constant. In practice it was found that the various datum points were not well fitted by a single line 
in Fig. 11 and instead there were different slopes for two different stages of annealing which are designated stages I and II. Table 1 summarizes the estimated grain growth exponents for stage I at very short times up to $\sim 5 \mathrm{~min}$ and stage II at longer times.

From these results it is apparent that grain growth occurs very rapidly in the first 5 min at 723 and $773 \mathrm{~K}$ and then reaches a steady state behavior with a lower value of $n$ whereas at $673 \mathrm{~K}$ the grain growth rate is low initially and thereafter there is a higher value of $n$ at times greater than $\sim 5$ min. These results establish that there are different grain growth kinetics for this alloy at lower and higher annealing temperatures and it is reasonable to anticipate that this difference will affect the measured values of the strain rate sensitivities in high temperature testing.

The variation of the grain size with annealing time as shown in Fig. 11 demonstrates that the traditional kinetic theory of grain growth as expressed by Eq. (1) does not adequately predict the total growth behavior and this matches a very early model developed specifically for grain growth kinetics [22]. An inherent assumption in this model is that the drag force is independent of the local grain size and this means in practice that the rate of grain growth is not controlled by the instantaneous grain size, $D$. On the contrary, it was argued that the decreasing difference between the ultimate limiting grain size, $D_{\mathrm{m}}$, and the changing value of the instantaneous grain size, $D$, can control the growth rate so that the growth relationship becomes

$$
\frac{D_{0}-D}{D_{m}}+\ln \left(\frac{D_{m}-D_{0}}{D_{m}-D}\right)=\frac{k_{0} t}{D_{m}^{2}} \exp (-Q / R T)
$$

where $D_{\mathrm{m}}$ is the limiting ultimate grain size for any selected annealing temperature and $k_{0}$ is a material constant. 
It follows, therefore, that by differentiating Eq. (2), the basic growth rate equation may be expressed as

$$
\frac{d D}{d t}=k\left(\frac{1}{D}-\frac{1}{D_{m}}\right)
$$

where the constant $\mathrm{k}$ is defined as $\mathrm{k} 0 \exp (-\mathrm{Q} / \mathrm{RT})$. Fig. 12a shows a linear representation of $\mathrm{dD} / \mathrm{dt}$ against $1 / D$ obtained at different annealing temperatures. According to Eq. (3), the value of $k$ can be obtained from the slopes of these lines at each temperature. Thus, the slopes of the lines in Fig. 12a increase with increasing temperature and thus it is concluded that the grain growth rate increases according to Eq. (3). Since $k$ has an Arrhenius type relationship with temperature, it follows that $k_{0}$ and $Q$ may be obtained by plotting $\ln (k)$ against $1 / T$ as demonstrated in Fig. 12b. This suggests that the material behavior can be divided into low temperature (673-723 K) and high temperature (723-773 K) regimes with activations energies of $\sim 147 \pm 5$ and $\sim 50 \pm 5 \mathrm{~kJ} \mathrm{~mol}^{-1}$ in these two regions, respectively.

The activation energy obtained for the low temperature regime is close to the value anticipated for lattice self-diffusion in $\mathrm{Mg}\left(\sim 135 \mathrm{~kJ} \mathrm{~mol}^{-1}\right.$ [23]) which shows that the growth process in this region is controlled by lattice self-diffusion. Other investigators have also reported similar results for grain growth of $\mathrm{Mg}$ alloys in this temperature range. For example, an activation energy of $\sim 111 \mathrm{~kJ} \mathrm{~mol}^{-1}$ was reported in the temperature range of 640-740 K for an AZ31 alloy processed by equal-channel angular pressing (ECAP) and containing $\mathrm{Al}_{2} \mathrm{O}_{3}$ particles [24] and in another investigation an activation energy of $\sim 109$ $\mathrm{kJ} \mathrm{mol}^{-1}$ was reported for an AZ31 alloy in the temperature range of $673-748 \mathrm{~K}$ after 4 ECAP passes [25].

The activation energy in the high temperature regime is lower than the activation energy of either lattice self-diffusion $\left(\sim 135 \mathrm{~kJ} \mathrm{~mol}^{-1}\right)$ or grain boundary diffusion $(\sim 92 \mathrm{~kJ}$ 
$\mathrm{mol}^{-1}$ [26]) in Mg. Nevertheless, similar low activation energies were also reported earlier for grain growth in $\mathrm{Mg}$ alloys although these values were obtained over lower temperature ranges. For example, an activation energy of $\sim 32 \mathrm{~kJ} \mathrm{~mol}^{-1}$ was reported for the AZ31 alloy at temperatures below $630 \mathrm{~K}$ [27] and it was related to the energy for the re-ordering of grain boundaries in the fine-grained material. Similarly, a low value of $Q$ in an AZ31 alloy, measured in the low temperature range of $473-673 \mathrm{~K}$, was attributed to the unrecrystallized microstructure where the non-equilibrium grain boundaries contained a large number of extrinsic dislocations [25]. In another investigation, activation energy of about $24 \mathrm{~kJ} \mathrm{~mol}^{-}$ ${ }^{1}$, obtained in the temperature range of 523-673 K, was related to the progressive decrease in dislocation density by enhanced recovery [27]. However, the present results are different because of the use of a higher range of temperature.

Inspection of Eq. (3) shows that the constant $k$ is a kinetic parameter related to the grain boundary mobility, $M$. It follows, therefore, that $k$ should increase with increasing temperature as observed in Fig. 12. However, according to the values of $k_{0}$ shown in Fig. $12 \mathrm{~b}, k_{0}$ decreases with increasing annealing temperature. Thus, $Q$ will decrease with increasing temperature to compensate for the effect of $k_{0}$. This means that, by considering the relation between $k$ and mobility, the pre exponential constant decreases but the mobility of the grain boundaries increases with temperature by reducing the height of the energy barrier during grain growth. Accordingly, it is concluded that the low activation energy obtained in the high temperature regime $(723-773 \mathrm{~K})$ is due to the increased mobility of the grain boundaries at high temperatures because less energy is then needed to overcome the obstacles to grain growth. 
Based on this analysis, it is concluded that grain growth of the $\mathrm{Mg}-9 \mathrm{Gd}-4 \mathrm{Y}-0.4 \mathrm{Zr}$ alloy is reasonably restricted up to temperatures as high as about $673 \mathrm{~K}$. This is high for conventional $\mathrm{Mg}$ alloys but it is noted that the $\mathrm{Mg}-\mathrm{Gd}-\mathrm{Y}-\mathrm{Zr}$ alloy showed significant grain growth at higher temperatures even when the annealing time was very short. This was shown to be due to a change in growth kinetics and the rate controlling mechanisms. In the temperature range of $673-723 \mathrm{~K}$ the grain growth is controlled by lattice self-diffusion and the growth rate increases at higher temperatures due to the increased mobility of the grain boundaries.

\section{Conclusions}

1. The grain growth kinetics of an extruded $\mathrm{Mg}-9 \mathrm{Gd}-4 \mathrm{Y}-0.4 \mathrm{Zr}$ alloy was investigated by isothermal annealing in the temperature range of $673-773 \mathrm{~K}$ for $5-120 \mathrm{~min}$. A grain growth map was developed, from which the grain growth severity could be obtained through grain growth factors for different combinations of annealing times and temperatures.

2. Grain growth was restricted at the lower annealing temperatures but there is enhanced grain growth at high temperatures. The grain growth is controlled by lattice selfdiffusion in the temperature range of $673-723 \mathrm{~K}$ but the increased mobility of the grain boundaries lead to a low activation energy for grain growth at temperatures in the range of $723-773 \mathrm{~K}$.

3. The $\mathrm{Mg}_{3}(\mathrm{Gd}, \mathrm{Y})$ precipitates showed sufficient thermal stability to restrict grain growth at high temperatures. These particles restrict grain growth by grain boundary pinning. 
4. The material revealed an unusual basal texture in the extruded condition, where the basal planes were aligned perpendicular to the extrusion axis. This was attributed to the high extrusion ratio and dynamic recrystallization, which can result in grain rotation due to growth advantage. The basal texture was weakened after annealing.

\section{Acknowledgement}

The authors thank the Iran National Science Foundation (INSF) for the support of this work under Grant No. 92028838. The work of one of us was supported by the European Research Council under ERC Grant Agreement No. 267464-SPDMETALS (TGL).

\section{References}

1. Mordike BL, and Ebert T (2001) Magnesium: Properties-applications-potential, Mater Sci Eng A 302:37-45.

2. Boehlert CJ (2007) The tensile and creep behavior of Mg-Zn Alloys with and without $\mathrm{Y}$ and $\mathrm{Zr}$ as ternary elements, J Mater Sci 42:3675-3684.

3. Liu K, Zhang J, Sun W, Qiu X, Huayi L, Dingxiang Tang LL, Rokhlin FM, and Elkin JM (2009) Effect of Zn concentration on the microstructures and mechanical properties of extruded Mg-7Y-4Gd-0.4Zr alloys, J Mater Sci 44:74-83.

4. Ning ZL, Wang GJ, Cao FY, Sun JF, and Du JF (2009) Tensile deformation of a $\mathrm{Mg}-2.54 \mathrm{Nd}-0.26 \mathrm{Zn}-0.32 \mathrm{Zr}$ alloy at elevated temperature, J Mater Sci 44:4264-4269.

5. Onorbe E, Garces G, Perez P, and Adeva P (2012) Effect of the LPSO volume fraction on the microstructure and mechanical properties of $\mathrm{Mg}-\mathrm{Y}_{2 \mathrm{X}}-\mathrm{Zn} \mathrm{x}$ alloys, $\mathrm{J}$ Mater Sci 47:1085-1093.

6. Hou Xi, Peng Q, Cao Zh, Shiwei Xu, Kamado Sh, Wang L, Wu Y, and Wang L (2009) Structure and mechanical properties of extruded Mg-Gd alloy sheet, Mater Sci Eng A 520: 162-167. 
7. Peng Q, Dong H, Tian Y, Zhang H (2012) Effect of backward extrusion on microstructure and mechanical properties of $\mathrm{Mg}-\mathrm{Gd}$ based alloy, Mater Sci Eng A 532: 443-448.

8. Movahedi-Rad A, and Mahmudi R (2014) Effect of Ag addition on the elevatedtemperature mechanical properties of an extruded high strength $\mathrm{Mg}-\mathrm{Gd}-\mathrm{Y}-\mathrm{Zr}$ alloy, Mater Sci Eng A 614:62-65.

9. Zhang X, Li L, Deng Y, and Zhou N (2009) Superplasticity and microstructure in $\mathrm{Mg}-\mathrm{Gd}-\mathrm{Y}-\mathrm{Zr}$ alloy prepared by extrusion, J Alloys Compd 481:296-300.

10. Cizek J, Prochazka I, Smola B, Stulikova I, Kuzel R, Matej Z, Cherkaska V, Islamgaliev RK, and Kulyasova O (2007) Microstructure and thermal stability of ultra fine grained Mg-based alloys prepared by high-pressure torsion, Mater Sci Eng A 462:121-126.

11. Li DJ, Wang QD, Blandin JJ, Suery M, Dong J, and Zeng XQ (2009) High temperature compressive deformation behavior of an extruded $\mathrm{Mg}-8 \mathrm{Gd}-3 \mathrm{Y}-0.5 \mathrm{Zr}$ (wt.\%) alloy, Mater Sci Eng A 526:150-155.

12. Yan H, Chen R, Zheng N, Luo J, Kamado S, and Han E (2013) Effects of trace Gd concentration on texture and mechanical properties of hot-rolled $\mathrm{Mg}-2 \mathrm{Zn}-\mathrm{xGd}$ sheets, J Mag Alloys 1:23-30.

13. Alizadeh R, Mahmudi R, and Langdon TG (2014) Superplasticity of a fine-grained $\mathrm{Mg}-9 \mathrm{Gd}-4 \mathrm{Y}-0.4 \mathrm{Zr}$ alloy evaluated using shear punch testing, J Mater Res Tech 3:228-232.

14. ASM Handbook, vol. 3, 1992.

15. Robson JD, Twier AM, Lorimer GW, and Rogers P (2011) Effect of extrusion conditions on microstructure, texture, and yield asymmetry in Mg-6Y-7Gd-0.5 wt\%Zr alloy, Mater Sci Eng A 528: 7247-7256.

16. Mackenzie L, and Pekguleryuz M (2008) The recrystallization and texture of magnesium-zinc-cerium alloys,Scripta Mater 59: 665-668.

17. Yan H, Xu SW, Chen RS, Kamado S, Honma T, and Han EH (2011) Twins, shear bands and recrystallization of a $\mathrm{Mg}-2.0 \% \mathrm{Zn}-0.8 \% \mathrm{Gd}$ alloy during rolling, Scripta Mater 64: 141-144. 
18. Basu I, and Al-Samman T (2014) Superior light metals by texture engineering: Optimized aluminum and magnesium alloys for automotive applications, Acta Mater 67: 116-133.

19. Hadorn JP, Hantzsche K, Yi S, Bohlen J, Letzig D, and Agnew SR (2012) Effects of solute and second-phase particles on the texture of Nd-containing Mg Alloys, Metall Mater Trans A 43A: 1363-1375.

20. Al-Samman T, and Li X (2011) Sheet texture modification in magnesium-based alloys by selective rare earth alloying, Mater Sci Eng A 528: 3809-3822.

21. Jie Kuang, Xiaohui Li, Xiaoxin Ye, Jianguo Tang, Haifeng Liu, Jeff Wang, Guoyi Tang (2015) Microstructure and texture evolution of magnesium alloys during electropulse treatment, Metall Mater Trans A 46: 1789-1804.

22. Burke JE (1949) Some factors affecting the rate of grain growth in metals, Trans TMS-AIME 180:73-91.

23. Frost HJ and Ashby MF (1982) Deformation Mechanisms Maps, Pergamon Press, Oxford, U.K., p. 44.

24. Radi $\mathrm{Y}$ and Mahmudi $\mathrm{R}$ (2010) Effect of $\mathrm{Al}_{2} \mathrm{O}_{3}$ nano-particles on the microstructural stability of AZ31 Mg alloy after equal channel angular pressing, Mater Sci Eng A 527:2764-2771.

25. Kim HK (2004) Activation energies for the grain growth of an AZ31 Mg alloy after equal channel angular pressing, J Mater Sci 39:7107-7109.

26. Sherby OD and Weertman J (1979) Diffusion-controlled dislocation creep: a defense, Acta Metall 27:387-400.

27. Kim HK and Kim WJ (2004) Microstructural instability and strength of an AZ31 Mg alloy after severe plastic deformation, Mater Sci Eng A 385:300-308. 


\section{Figure captions}

Fig. 1 Optical micrographs of the: (a) transverse, and (b) longitudinal directions of the asextruded material. (c) Grain size distribution of the transverse direction.

Fig. 2 SEM micrographs of the alloy, showing the morphology of the precipitates.

Fig. 3 EDS line- and point-scan results of the extruded material.

Fig. 4 Microstructure and grain size distributions of the material after annealing.

Fig. 5 SEM micrographs after annealing for 120 min at: $673 \mathrm{~K}$ (a and b), $723 \mathrm{~K}$ (c and d), and $773 \mathrm{~K}$ (e and f).

Fig. 6 EDS line- and point-scan results of the alloy after annealing for $120 \mathrm{~min}$ at; (a) 723 $\mathrm{K}$, and (b) $773 \mathrm{~K}$.

Fig. 7 The EBSD orientation maps and the corresponding misorientation histograms before ( $\mathrm{a}$ and $\mathrm{b}$ ) and after annealing at $723 \mathrm{~K}$ for $120 \mathrm{~min}$ (c and d).

Fig. 8 Pole figures of the material in the: (a and b) extruded, and (c and d) annealed (673 $\mathrm{K}, 120 \mathrm{~min}$ ) conditions.

Fig. 9 The variation of average grain size with annealing time at different temperatures.

Fig. 10 Grain growth map, showing the grain growth factor at the investigated temperatures and annealing times.

Fig. 11 Re-plotting the data of Fig. 9 on a $\log$-log scale to obtain $n$-values according to Eq. (1).

Fig. 12 (a) plot of $\mathrm{d} D / \mathrm{d} t$ against $1 / D$ to determine the $k$ parameter in Eq. (3), and (b) plot of $k$ against $1 / T$ on a semi log scale to calculate activation energies according to the Burke's model.

Table 1 Grain growth exponents for stages I (short times) and II (long times) at different temperatures 

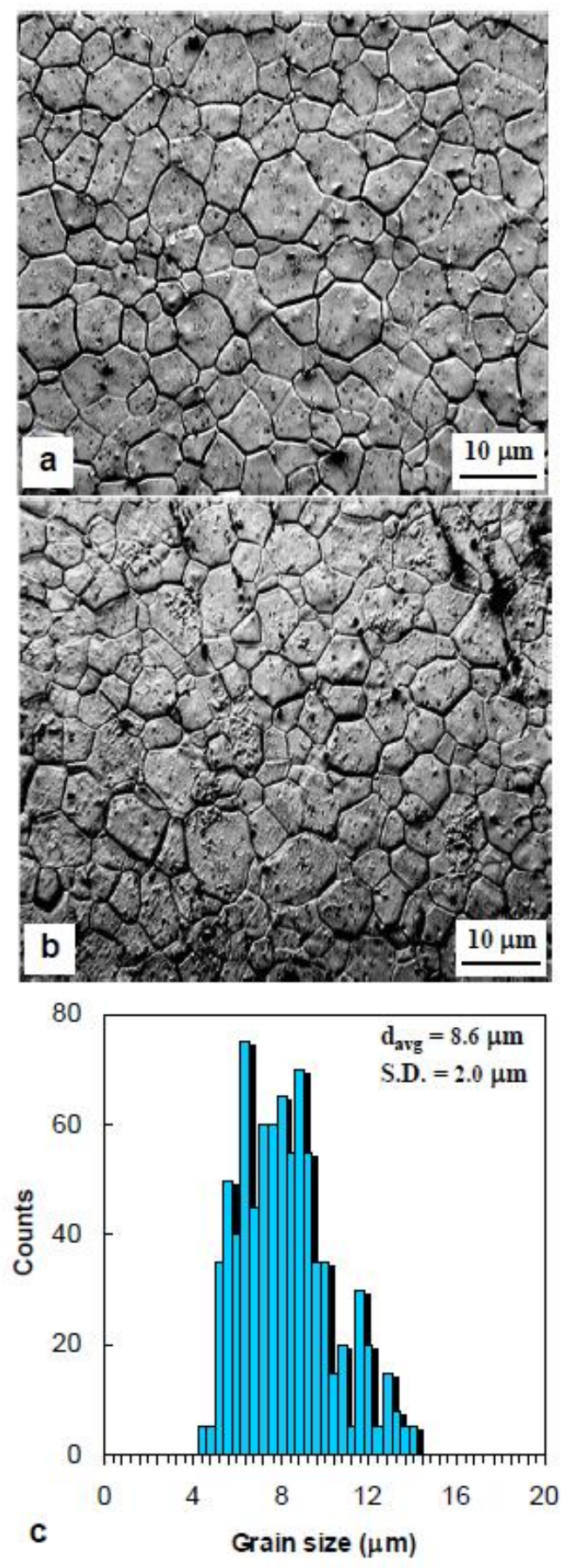

Figure 1 

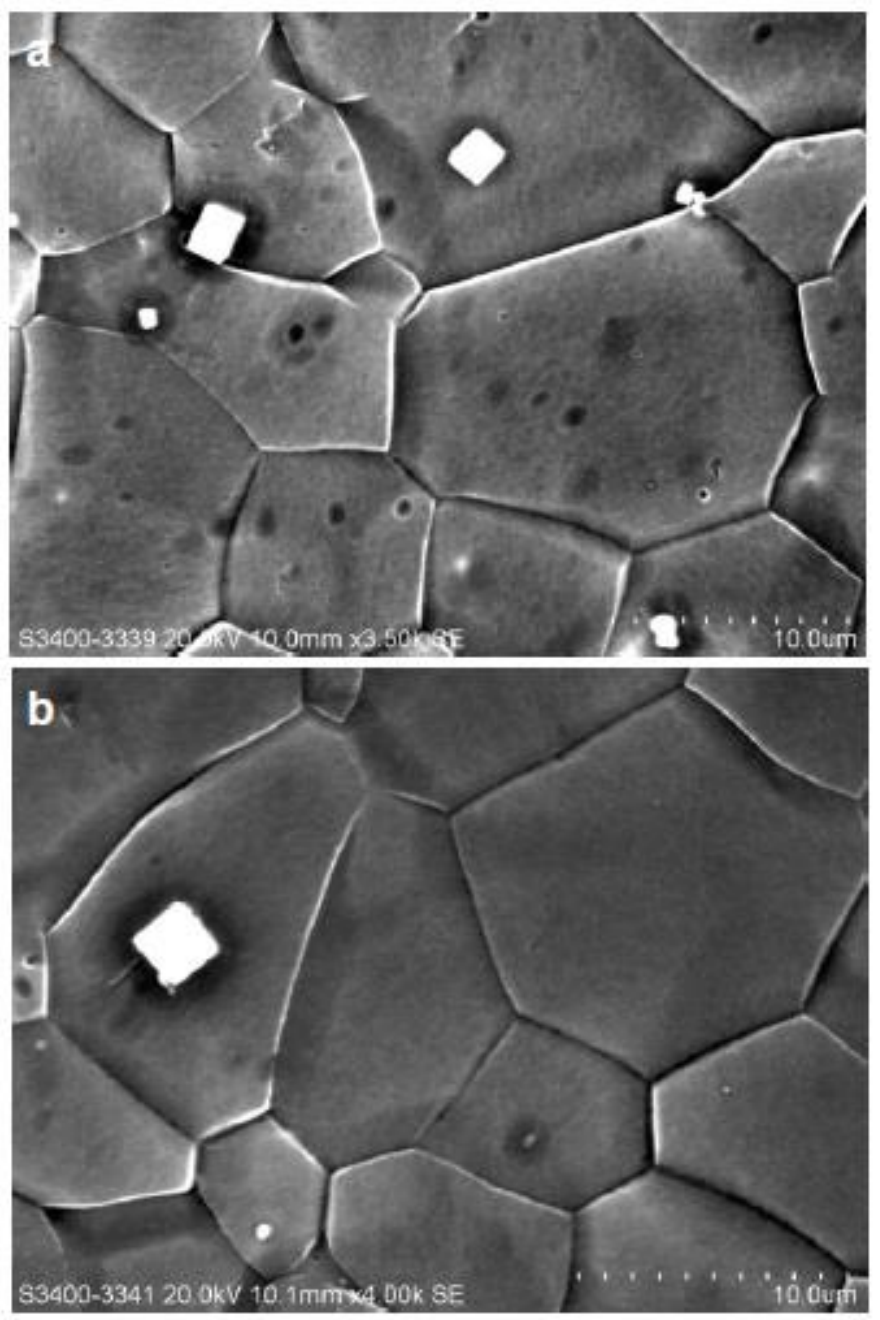

Figure 2 

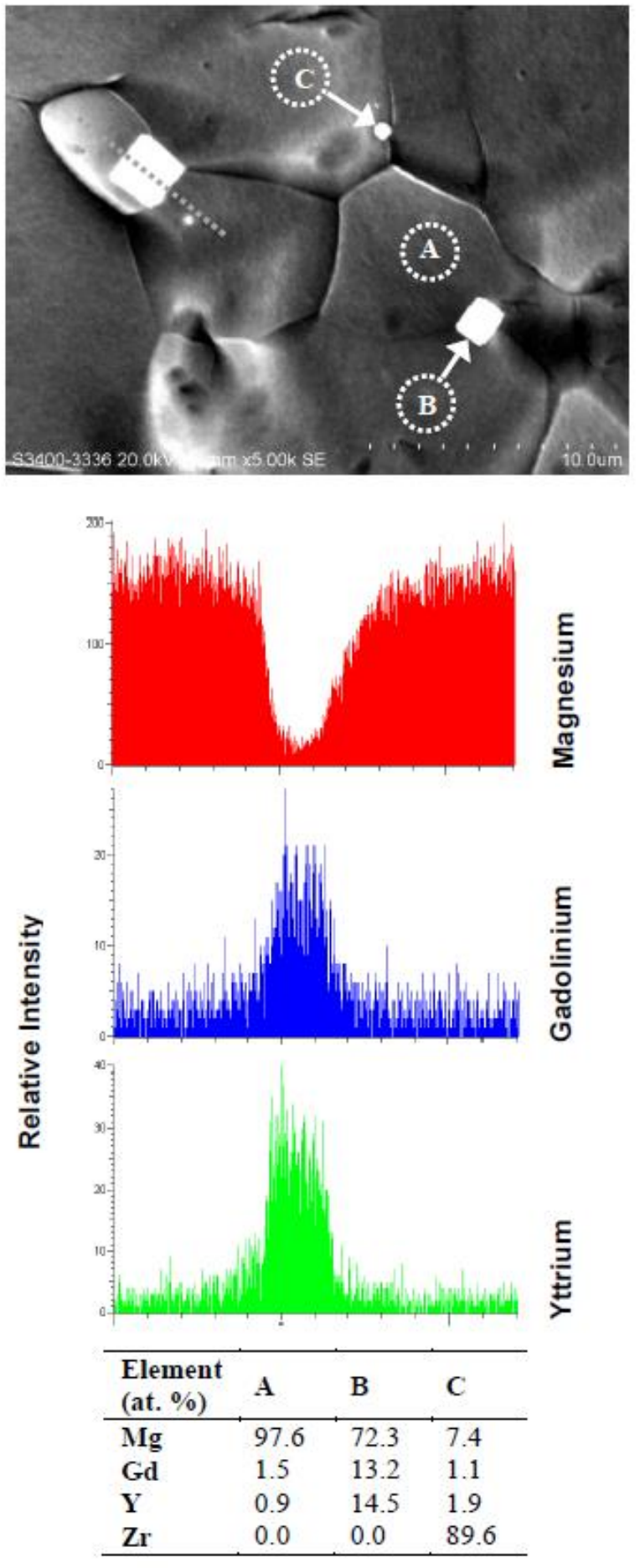

Figure 3 

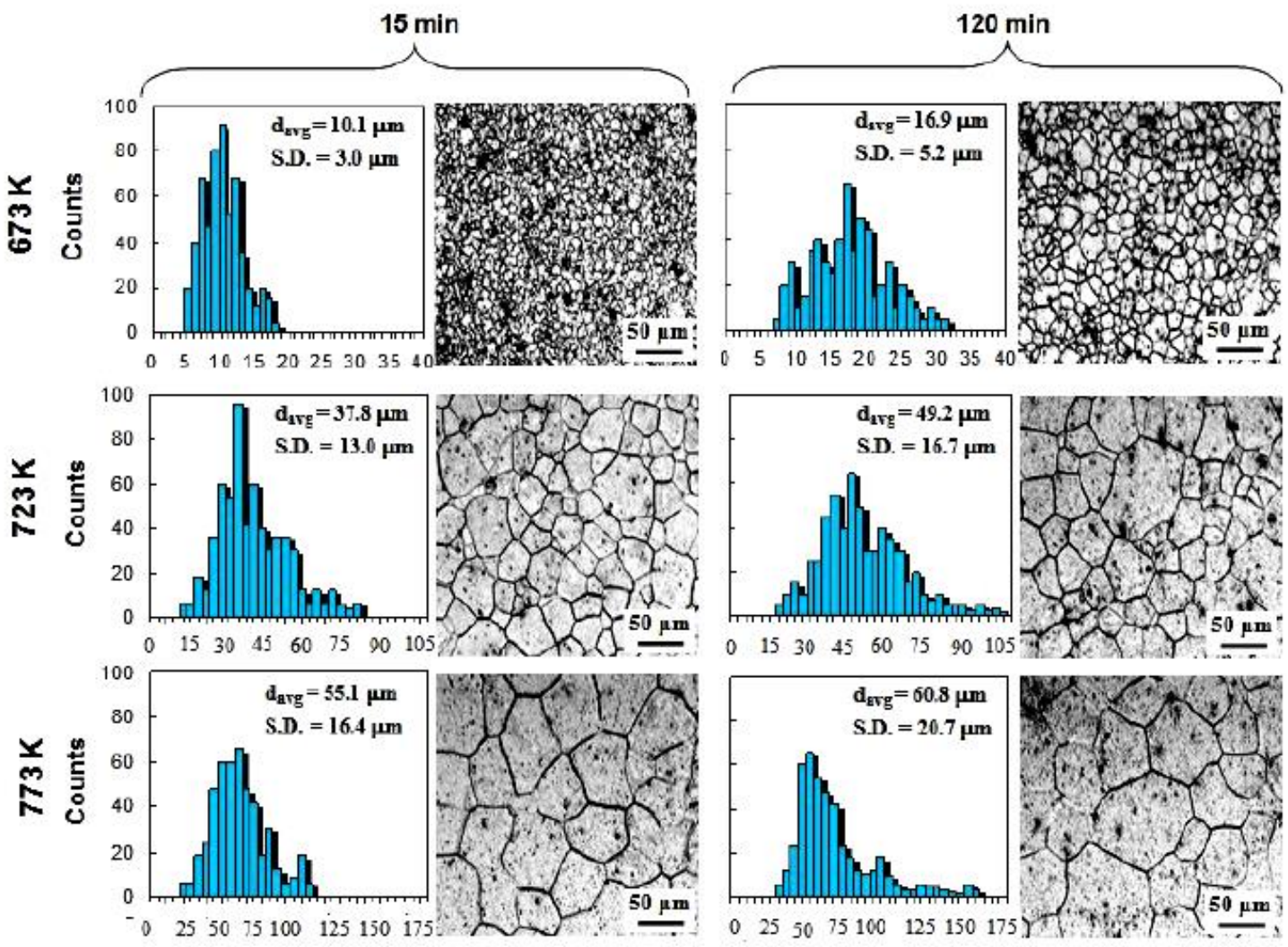

Grain size ( $\mu \mathrm{m})$

Grain size $(\mu \mathrm{m})$

Figure 4 

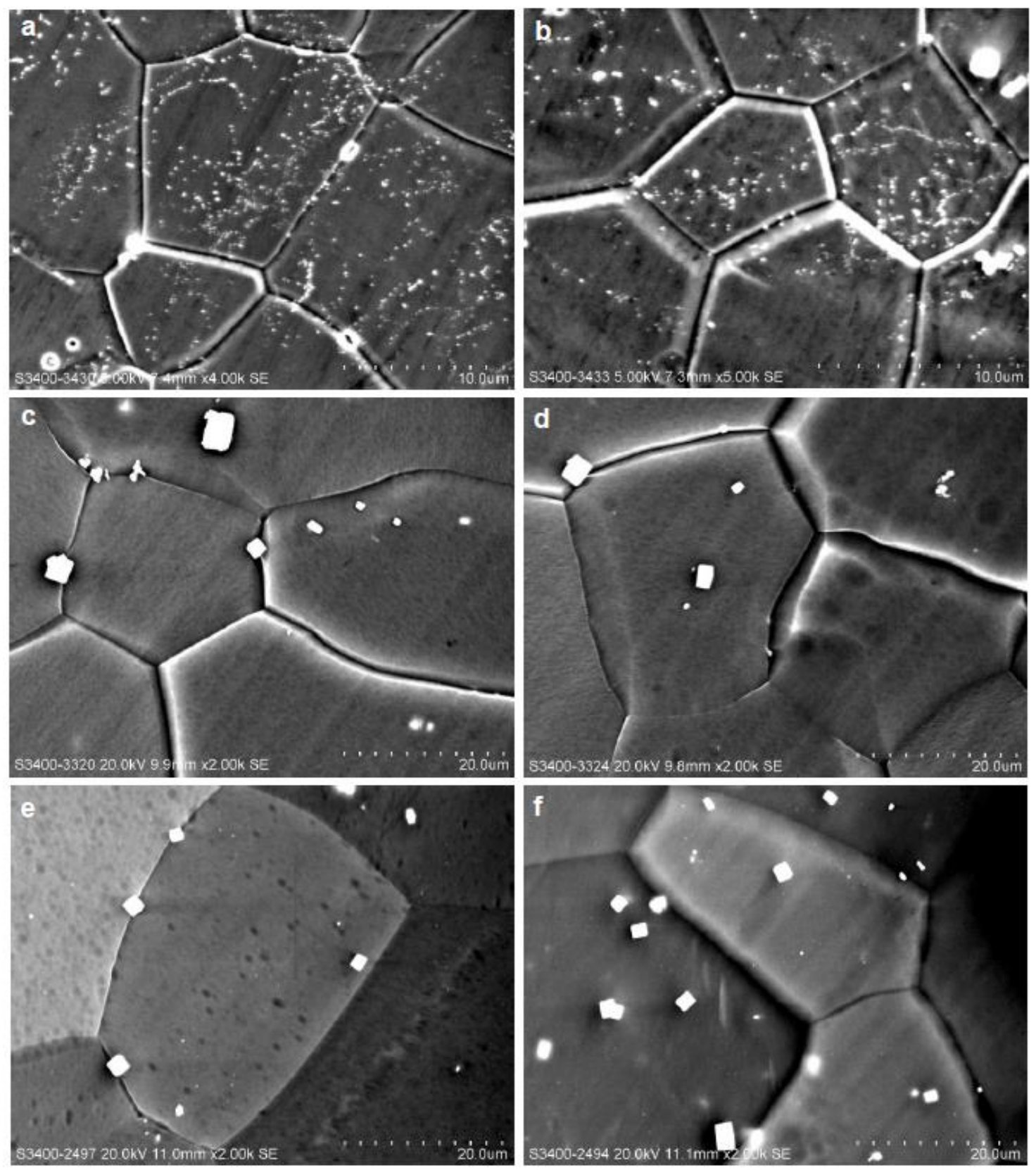

Figure 5 

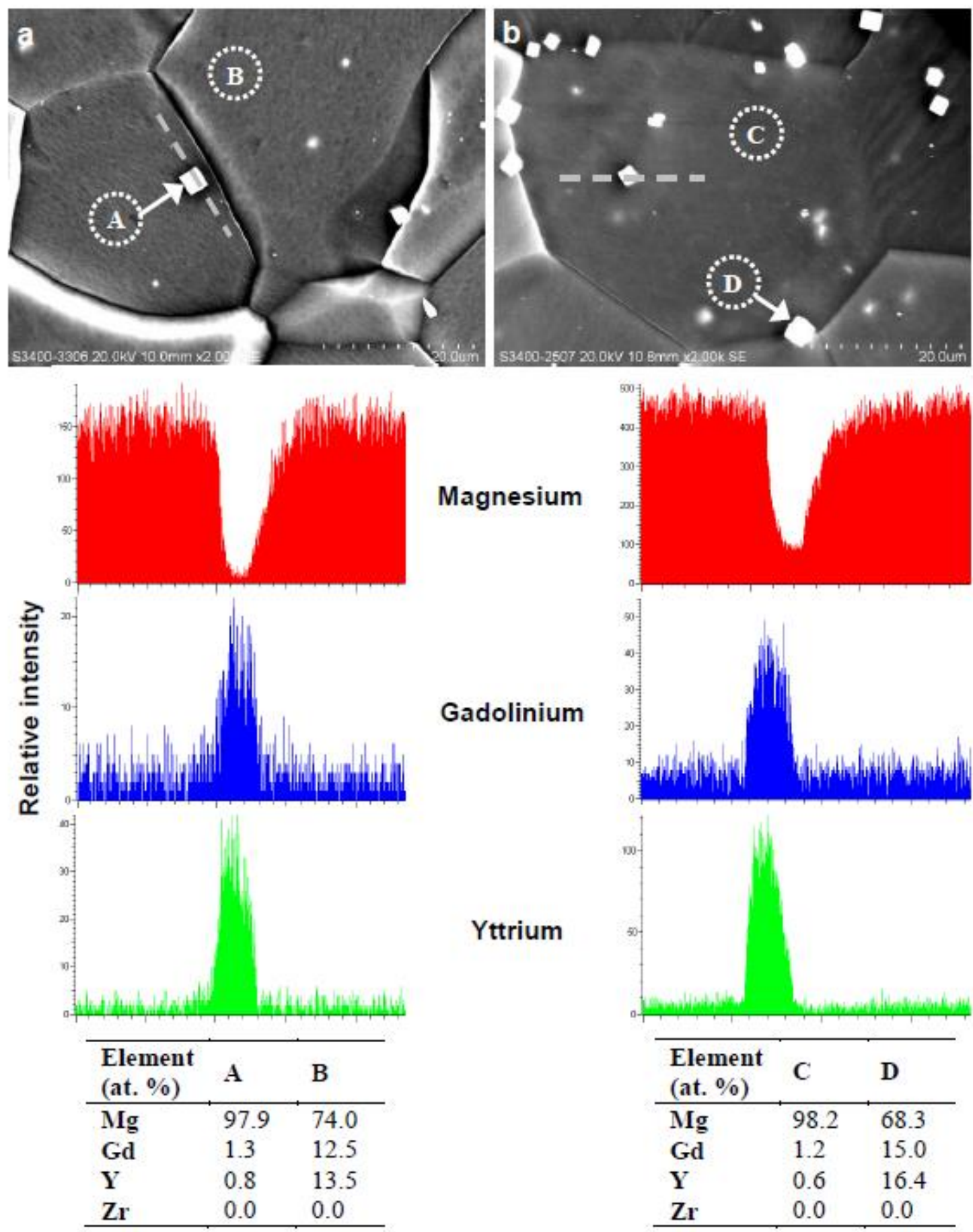

Figure 6 

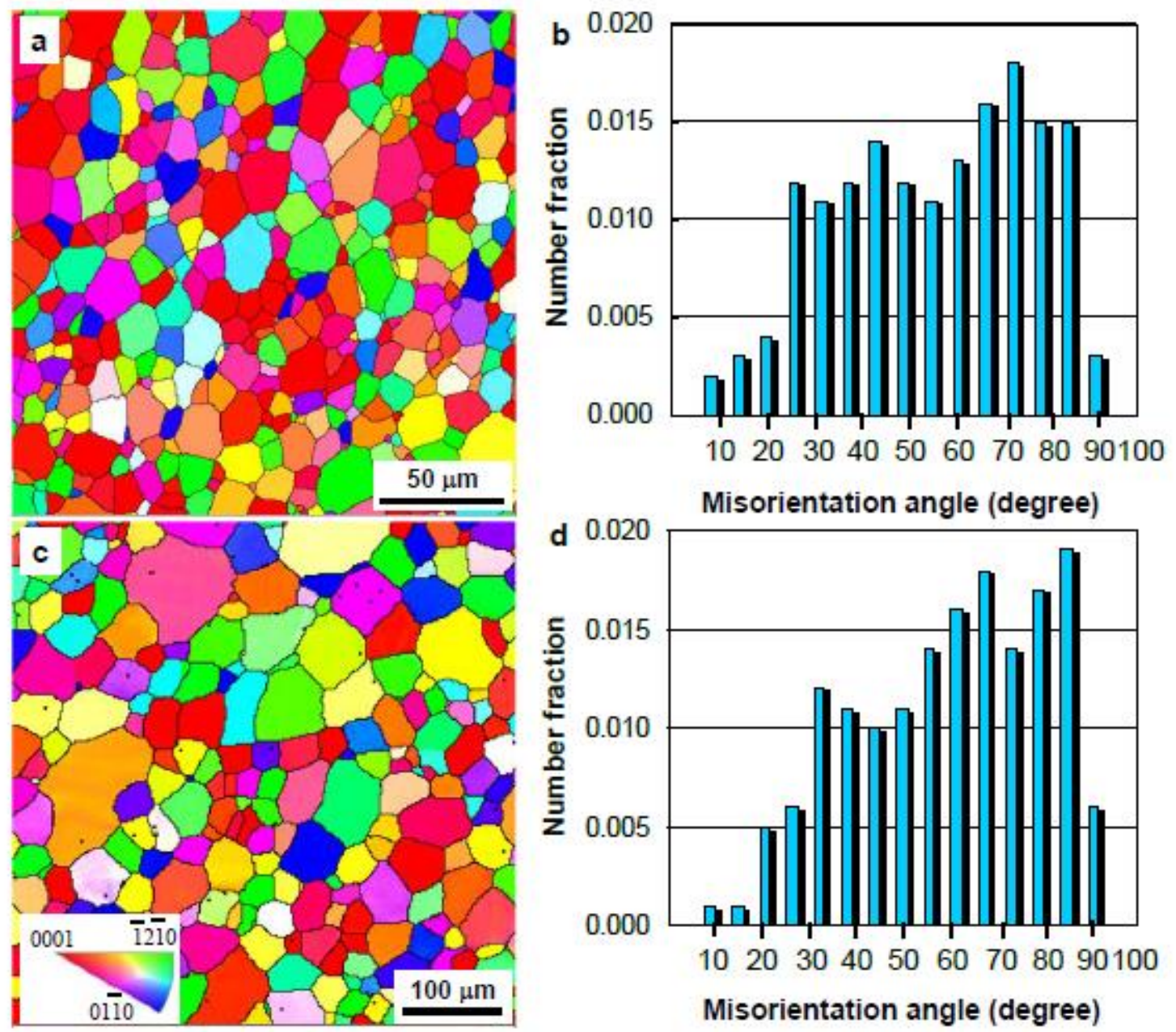

Figure 7 


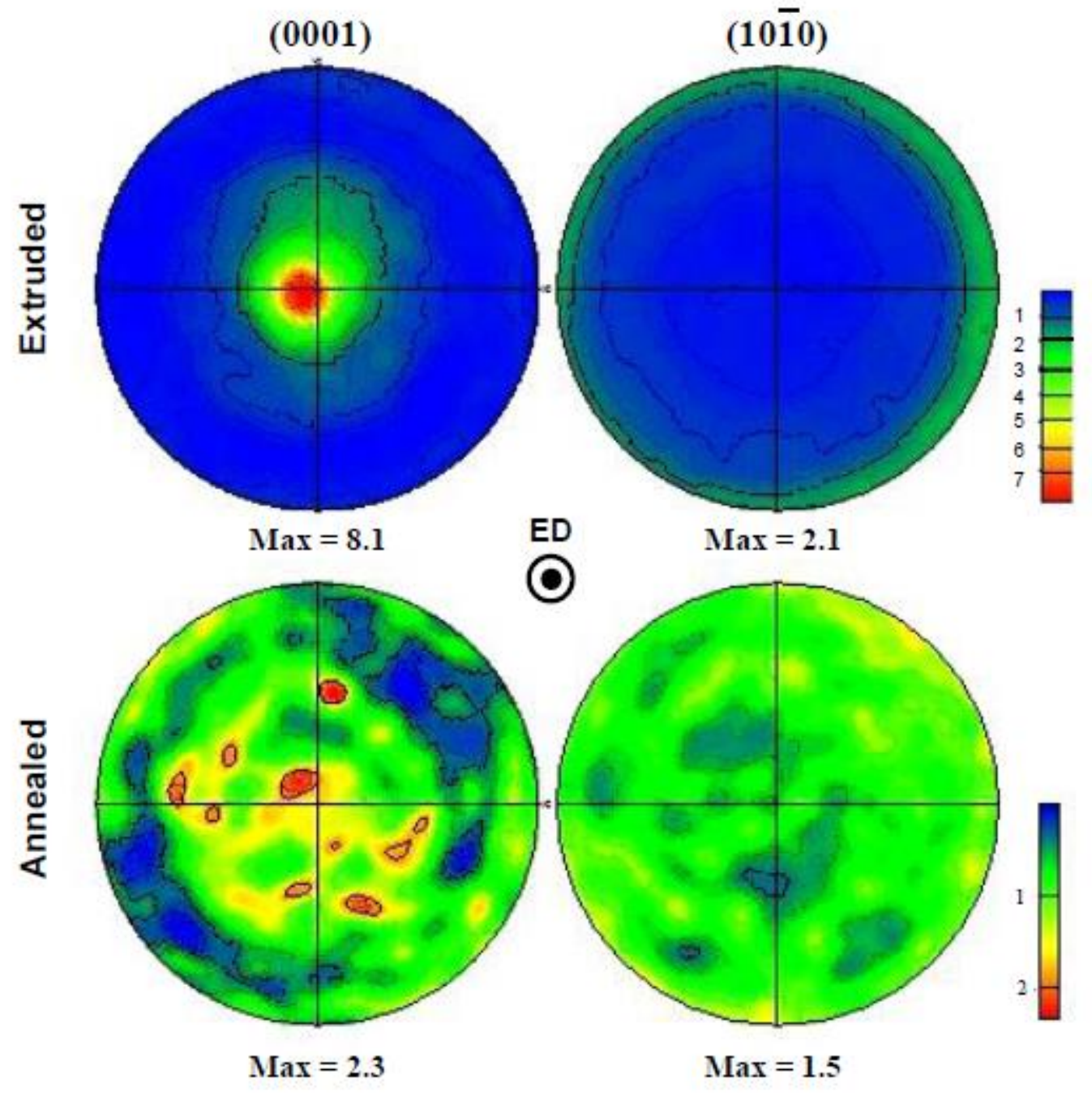

Figure 8 


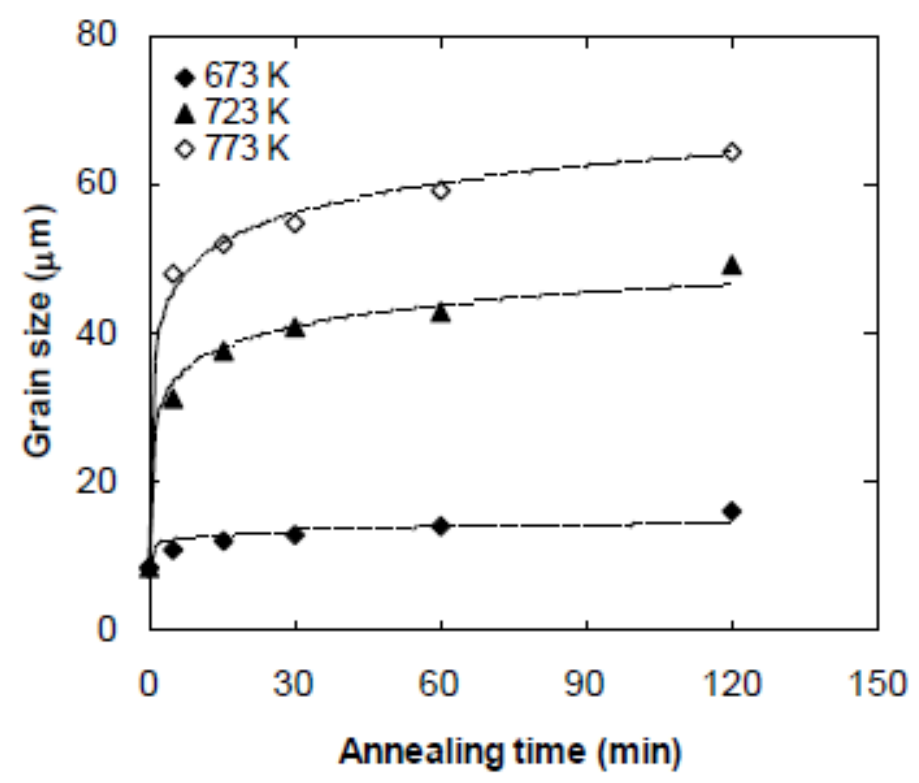

Figure 9

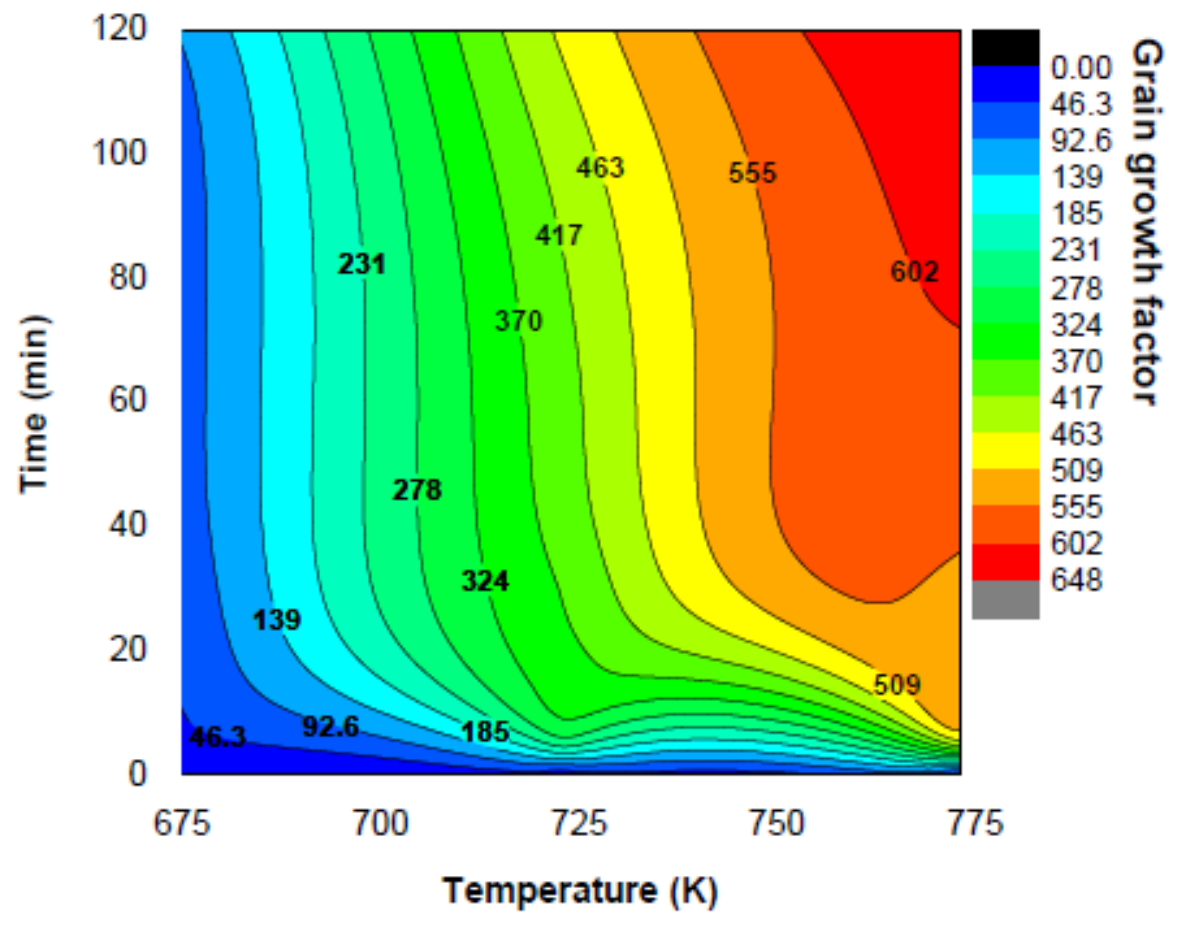

Figure 10 


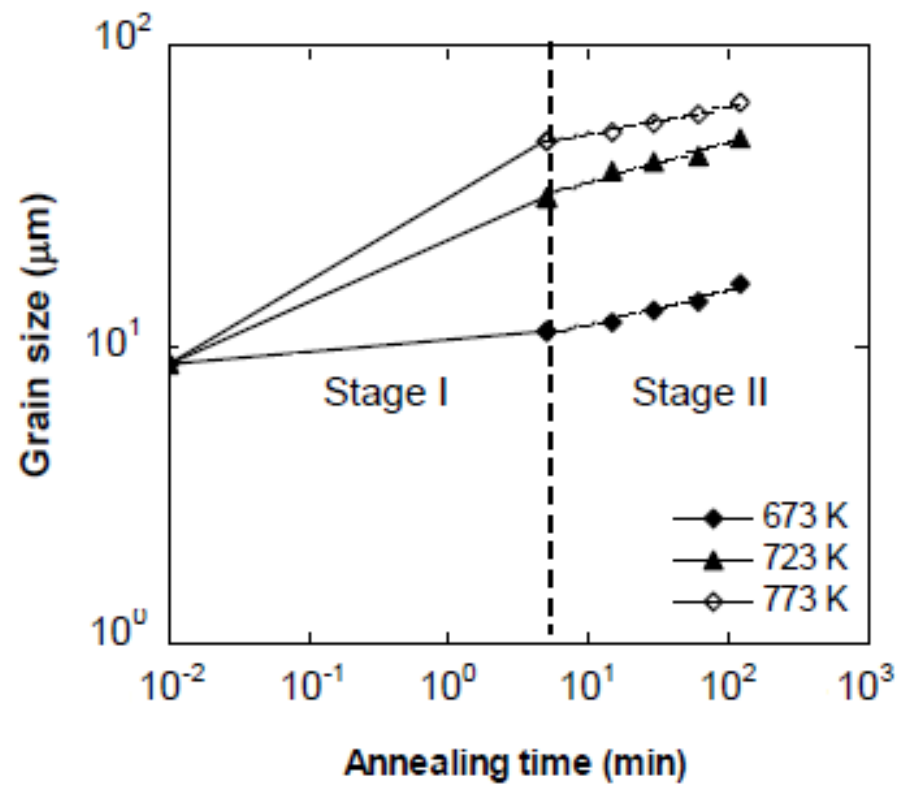

Figure 11 

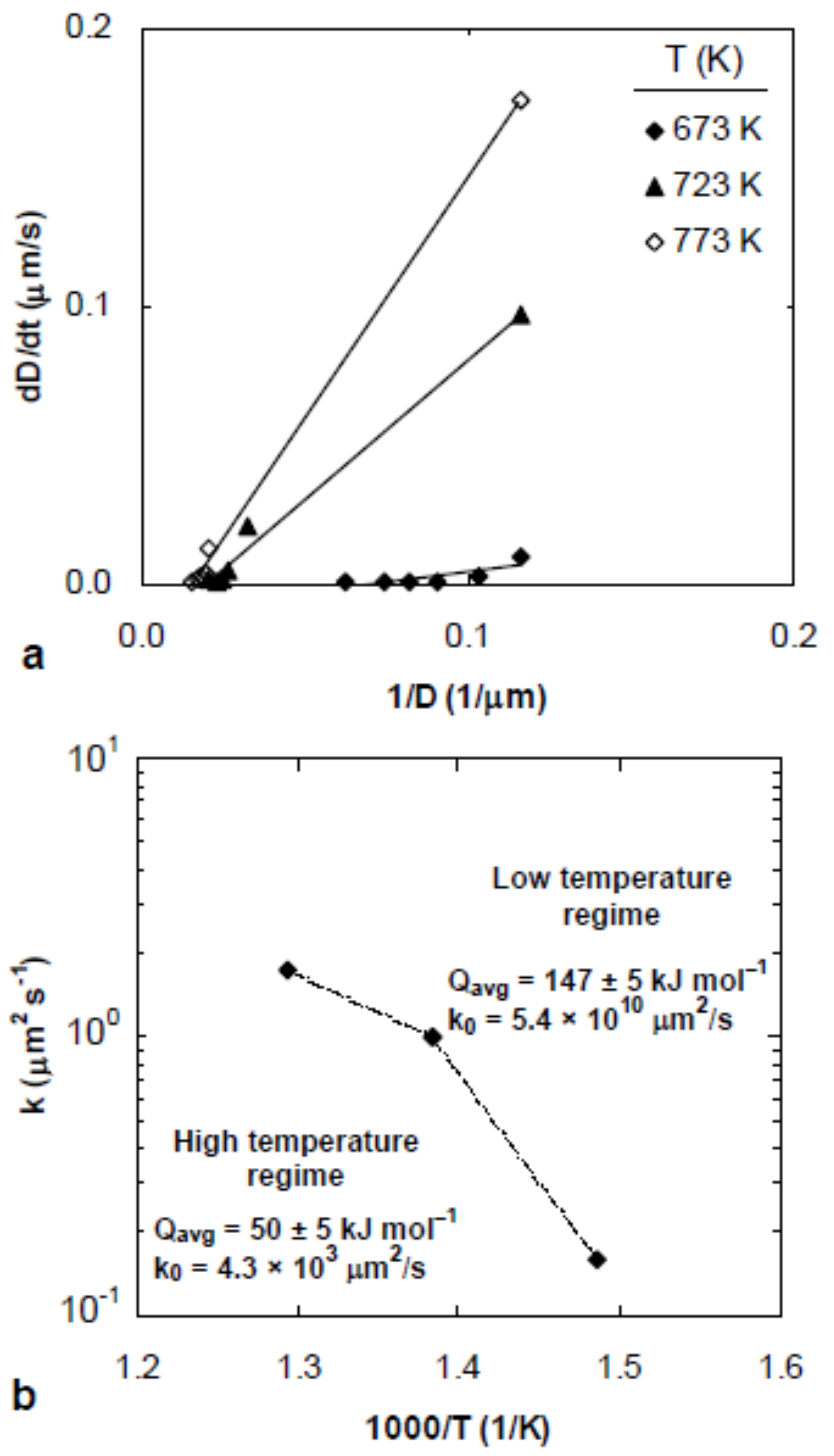

Figure 12

Table 1 Grain growth exponents for stages I (short times) and II (long times) at different temperatures

\begin{tabular}{ccc}
\hline Temperature & \multicolumn{2}{c}{$n$} \\
\cline { 2 - 3 }$(\mathrm{K})$ & stage I & stage II \\
\hline 673 & 0.04 & 0.11 \\
723 & 0.21 & 0.13 \\
773 & 0.28 & 0.09 \\
\hline
\end{tabular}

